\title{
Boiling Frogs: Pricing Strategies for a Manufacturer Adding a Direct Channel that Competes with the Traditional Channel
}

\author{
Kyle Cattani $^{1}$ \\ Wendell Gilland $^{1}$ \\ Hans Sebastian Heese ${ }^{2}$ \\ Jayashankar Swaminathan ${ }^{1}$
}

${ }^{1}$ The Kenan-Flagler Business School, The University of North Carolina at Chapel Hill
${ }^{2}$ Kelley School of Business, Indiana University

January, 2005 


\title{
Boiling Frogs: Pricing Strategies for a Manufacturer Adding a Direct Channel that Competes with the Traditional Channel
}

\begin{abstract}
In this paper, we analyze a scenario where a manufacturer with a traditional channel partner (i.e., a retailer) opens up a direct Internet channel that is in competition with the traditional channel partner. We first consider that in order to mitigate channel conflict the manufacturer, who chooses wholesale prices as a Stackelberg leader, commits to setting a direct channel retail price that matches the retailer's price in the traditional channel. Under this general equal-pricing strategy, we determine the effect of more specific pricing strategies on prices and profits of the manufacturer and the retailer. These specific strategies are: (1) keep wholesale prices as they were before, (2) keep retail prices as they were before, or (3) select wholesale and retail prices that optimize profits for the manufacturer. Within these strategies we identify and summarize cases when the resulting prices are lower than the pre-Internet prices, and when they are higher, relating them to the respective channel costs and to the relative convenience to the consumer of the Internet channel. We find that Strategy 3 - the specific equal-pricing strategy that optimizes profits for the manufacturer - often is also preferred by the retailer and customers (through lower prices) over the other equal-pricing strategies. We next consider the implications of the equal-pricing constraint through a numerical experiment that indicates that the equal-pricing strategy is appropriate as long as the Internet channel is significantly less convenient than the traditional channel. If the Internet channel is of comparable convenience to the traditional channel, then the manufacturer has tremendous incentive to abandon the equal-pricing policy - at great peril to the traditional retailer.
\end{abstract}

Keywords: Supply Chain Management; Multiple Channels; Direct Channel; Retail Channel;

Channel Conflict; Pricing; Game Theory. 


\section{Introduction}

The introduction by a manufacturer of a new, Internet-based distribution channel provides an opportunity to increase sales and/or decrease costs. An increased customer base may become accessible, and the marginal cost of reaching these customers may be negligible. On the other hand, the introduction of a new channel may threaten existing channel relationships. The challenge of appeasing current channel partners is problematic for many manufacturers that might otherwise quickly adapt to and experiment with an Internet-based outlet. Some manufacturers, such as Daimler-Chrysler, Nikon, and Rubbermaid, thus have used the Internet as a medium to provide information about their products and/or to point the Internet surfer to the nearest retailer carrying the product, but do not offer the product for sale over the Internet. Many other manufacturers offer the product for sale over the Internet, but only at full-retail price, presumably to prevent a channel conflict with existing distributors. For example, a replacement tricolor ink cartridge for the widely used Hewlett Packard (HP) Deskjet 600 series printer can be obtained for \$31.99 at the manufacturer's (HP) web site. This price matches exactly the non-sale price at HP's traditional retailers such as Best Buy.

In Table 1, we display a sample of recent prices charged for several products that are sold both through a manufacturer's web site and through traditional retailers. For these examples of products in several categories, including electronics, athletic equipment, and toys, we note that the Internet price charged by the manufacturer and the in-store price charged by a traditional retailer are exactly or nearly identical. We are unaware of any comprehensive empirical study comparing prices between manufacturer-owned web sites and traditional retail locations, although a recent survey by Ernst\&Young (2001) reports that nearly two thirds of companies price products identically for their on-line and off-line operations.

\begin{tabular}{|l|c|c|}
\hline \multicolumn{1}{|c|}{ Product } & $\begin{array}{c}\text { Manufacturer's } \\
\text { Web Price }\end{array}$ & $\begin{array}{c}\text { Traditional } \\
\text { Retail Price }\end{array}$ \\
\hline Sony 32" Flat Tube HDTV & $\$ 1,299.99$ & $\$ 1,299.99^{1}$ \\
\hline Sony 57" HD Projection TV & $\$ 2,299.99$ & $\$ 2.299 .99^{1}$ \\
\hline Adidas Climacool 2 M Shoes & $\$ 100.00$ & $\$ 99.99^{2}$ \\
\hline Nike Air Kantara Shoes & $\$ 120.00$ & $\$ 119.99^{2}$ \\
\hline Nike Triax Stamina Watch & $\$ 129.00$ & $\$ 129.00^{2}$ \\
\hline LEGO Snowboard Superpipe & $\$ 49.99$ & $\$ 49.23^{3}$ \\
\hline
\end{tabular}

${ }^{1}$ Best Buy $\quad{ }^{2}$ Dick's Sporting Goods ${ }^{3}$ Wal-Mart

Table 1: Price Comparison of Selected Products (September, 2003) 
In some product categories, we are beginning to see examples where prices on the manufacturer's website are lower than prices in the traditional retail channel. The CD Los Lonely Boys can be purchased at Sony.com for $\$ 10.98$, while it was simultaneously priced at $\$ 13.88$ at Wal-Mart and $\$ 13.99$ at Best Buy. Quicken Deluxe, a personal financial software program, is available online at Quicken.com for \$49.95, yet costs $\$ 10$ more at both Best Buy and Office Depot. As will be discussed later, our research provides theoretical justification for why this pricing behavior may be emanating from the music and software industries.

This paper is motivated from our interactions with managers at a leading computer manufacturer who were considering the introduction of a direct channel that would be in competition with their traditional channel. The managers sought insights about the effect of different pricing strategies on profitability to both the manufacturer and the traditional channel partners.

We thus explore a scenario where a manufacturer with a traditional channel partner (i.e., a retailer) opens a direct channel that is in competition with the traditional channel. For our discussion we will consider the direct channel to be Internet based, although it could be any direct channel. We begin with the assumption that the manufacturer, who is a Stackelberg leader, chooses wholesale prices for the traditional channel along with retail prices for the direct channel in such a way that the retail prices in the traditional channel and the direct channel are identical, consistent with prevalent practice.

Given this general assumption of equal prices across the two channels, we use consumer utility theory to develop a model that determines the effect on profits and market shares of the manufacturer and the retailer for specific strategies that keep wholesale prices as they were before (Strategy 1), keep retail prices as they were before (Strategy 2), or set wholesale and retail prices to optimize the manufacturer's profit (Strategy 3). For each of these strategies, we determine how the resulting prices compare to the singlechannel prices, and we determine the resulting profits for the supply chain and its two players. Counter to our intuition, we find that the pricing strategy that optimizes the manufacturer's profit (Strategy 3) also tends to be preferred by the retailer over the other two strategies. Surprisingly, the end customer also prefers Strategy 3 in most cases, benefiting from lower prices. This is in contrast to Strategy 1, which creates upward pressure 
on retail prices. In general, we conclude that under an equal-pricing framework, the retailer does not need to view the manufacturer's addition of a direct channel as harmful competition but rather as a mechanism for segmenting the market in a way that benefits both the manufacturer and the retailer.

We next show, through a numerical experiment, that the equal-pricing strategy is reasonable for the manufacturer as long as the Internet channel is significantly less convenient and/or more costly than the retail channel. If the Internet channel becomes more convenient and less costly than the traditional channel, we show that an equal-pricing strategy significantly restricts profits for the manufacturer, who at this point has tremendous incentive to use the direct channel to undercut traditional channel prices. In doing so, the manufacturer's large gains in profit come at the retailer's expense. Thus, the manufacturer's introduction of a direct channel that competes with a traditional channel has very different effects on the retail partner depending on the manufacturer's pricing strategy, which itself is affected by the relative costs and convenience of the two channels.

We propose an analogy to the parable of the boiling frog. The parable states that a frog thrown into a pot of boiling water will quickly jump out. But a frog thrown into a pot of temperate water may stay even if the temperature is slowly raised to boiling, leading to the untimely demise of the frog. By introducing an Internet channel with equal pricing, the manufacturer has placed the retailer in a mildly competitive position where the retailer may even benefit if the Internet is more costly and less convenient on average to the population of customers. But if, as we imagine, the costs and average convenience of the Internet channel become more favorable over time, then the manufacturer will be in a position to use the direct channel to undercut the prices in the traditional channel - and "boil" the traditional retailer.

The rest of the paper is organized as follows. In section 2, we discuss related literature. We introduce the demand generation model and present our analytical model and results in section 3 . We provide computational insights in section 4 and conclude in section 5.

\section{Related Literature}

There are a number of recent papers that study issues related to supply chains in e-business. Swaminathan and Tayur (2003) in their comprehensive review of analytical models related to Internet-based 
supply chains identify managing multiple distribution channels (that include an Internet channel) as one of the key areas of supply chain research. Cattani et al. (2004b) survey recent research related to the coordination of traditional and Internet supply chains while Tsay and Agrawal (2004a) review competitive models of traditional and Internet supply chains.

Jeuland and Shugan (1983) define channel coordination as the setting of all manufacturer- and retailer-controlled variables at the levels that maximize channel profits. Our paper relates to work done toward understanding the conflicts that arise given the different objectives of channel members. In contrast to much of the previous research, our paper assumes that the manufacturer is not only a channel partner of the retailer, but also competes with the retailer for end-customer sales.

In this paper, we extend the model introduced by Cattani et al. (2004a), who study a scenario where a retailer offers identical products via two channels that are perceived as different by the customers (e.g., traditional and Internet). In their model, customer utility for a specific product is decreasing in the price of the product and in the effort required (based on the particular channel) to purchase the product. Customers are not excluded from a specific channel - both channels have an opportunity to compete for all customers. Using a view that a product is a compilation of product and delivery attributes, the market is segmented based on the utility each customer attains from products delivered through either the direct channel or the traditional channel. In this current work, we apply their model in a different setting where a manufacturer with a traditional retail channel partner introduces a second channel in competition to the traditional channel.

Tsay and Agrawal (2004b) consider the channel conflicts that arise as a company engages in direct sales in competition with existing reseller partners. Their model allows demand in both channels to be stimulated by costly sales effort in either channel, with the direct channel facing an inherent cost disadvantage for providing sales effort. They assume the retail price is given, and focus attention on the impact of channel structure on optimal sales effort and the resulting profits. They conclude that the addition of a direct channel alongside a reseller channel is not necessarily detrimental to the reseller, particularly when the direct channel faces a significant disadvantage in the cost of sales effort and/or advantage in cost of fulfillment. Our model explicitly captures the heterogeneity in customer preferences for each channel, which 
Tsay and Agrawal acknowledge, but do not incorporate into their model. We also allow the retail price to change, which enables the supply chain participants to more fully react to the altered channel structure. When the direct channel is relatively inconvenient, our results are similar to Tsay and Agrawal in that we find that the addition of a direct channel is not necessarily detrimental to the reseller. But if the direct channel is relatively convenient, we find that the manufacturer has incentive to set wholesale and retail prices that adversely affect reseller profits.

Price competition between independent retailers and manufacturer-owned stores also is studied by Ahn et al. (2002). Their model assumes that manufacturer-owned stores are geographically isolated from the traditional retailers (i.e., they consider outlet stores on the periphery of metropolitan areas). The equilibrium pricing strategy is always one of three: monopoly, competition, or elimination. Our research follows up on the idea of market segmentation with a somewhat different approach. In our model, customer's net utility depends on the innate utility of the product reduced by the price and the effort required to acquire the product. In a traditional channel, effort might be associated with the physical distance from the traditional retailers, while in a direct channel effort might be associated with ease, convenience, and customer comfort with the channel. The market is segmented according to the utility each customer attains from either the direct channel or the traditional channel. In our model, customers are not excluded from a specific channel; thus both channels compete for all customers.

Bell et al. (2003) explore the effect of partial integration on retailer behavior. Using a linear demand model that considers prices and efforts of independent retailers competing against an integrated retailer (who invests in brand support), they find that prices charged by the independent retailer are higher than the prices charged when competition is between independent retailers only. While we do not consider brand support, we also find that retail prices can be higher with the entry of an integrated channel, but in our utility driven demand function model this scenario arises when the manufacturer acts suboptimally.

Boyaci (2004) considers a setting similar to ours, where a manufacturer sells through both a direct channel and a traditional retail channel, but his research focuses on the misaligned stocking decisions under demand uncertainty and on developing mechanisms for supply chain coordination. In another paper with a 
focus on inventory management, Seifert et al. (2001) assume that a manufacturer has a direct (Internet) market that serves a different customer segment than the traditional retail channel (not owned by the manufacturer). They model the inventory decisions for a supply chain comprised of a manufacturer and $N$ retailers. They compare a dedicated supply chain to a cooperative supply chain. In a dedicated supply chain the inventory sent to each retailer is used exclusively to meet demand at that retailer while inventory at the Internet store is used exclusively to meet demand at that store. In a cooperative supply chain, leftover inventory at the retailers is available to fill demand at the Internet store. They develop models that allow them to compare the benefits of supply-chain integration versus the benefits of supply-chain cooperation. In our models, the manufacturer and the retailer compete in the same market.

Chiang et al. (2003) conceptualize the impact on supply chain design of customer acceptance of a direct channel as a substitute for shopping at a traditional store. They conclude that direct marketing, which indirectly increases the flow of profits through the retail channel, helps the manufacturer improve overall profitability by reducing the degree of double marginalization. The direct channel may not always be detrimental to the retailer since it will be accompanied by a wholesale price reduction. We model an identical supply chain structure but use an alternate model that allows the direct channel to be preferred to the traditional channel, for at least some customers. Our model also differs in how we model the customer's willingness to pay in each channel: we model the customer utility for the two channels as separate (and independent) dimensions, while they consider the utility received by a specific customer from the direct channel to be a fraction $\theta$ (with $0<\theta<1$ ) of the utility received from the traditional channel, using $\theta$ for all customers. Similar to their results we find that the introduction of a direct channel can sometimes benefit the existing retailers. In contrast to their models, we find that supply chain benefits arise from the manufacturer actively participating in the direct channel, as opposed to the mere threat of direct channel sales.

Hendershott and Zhang (2004) analyze a model with a manufacturer and multiple, heterogeneous retailers. Consumers incur search costs, so in the absence of a direct channel they will purchase a product from the first retailer they discover that offers a price below a threshold value. When the manufacturer is able to offer the product directly to consumers, conditions are developed under which the manufacturer only sells 
through the traditional channel, only sells through the direct channel, or sells through both channels. The hybrid market structure arises only when the direct channel is more attractive to all customers and the transaction costs for the web fall within a specified range. This paper does not consider price matching in the direct channel or customers with heterogeneity in their channel preference.

\section{Model}

We consider a supply chain structure where a manufacturer sells to a retailer as well as in a direct channel, similar to the structure of the supply chains in Tsay and Agrawal (2004b), Seifert et al. (2001), and Chiang et al. (2003), but we use a formulation that explicitly models the channel preferences of heterogeneous customers. This customer utility model, which we summarize briefly in this paper, is similar to Cattani et al. (2004a), although this research assumes that both the retailer and manufacturer are active players.

We model an individual customer with a utility function for a product sold by a firm, where the customer's utility for the product is decreasing in the price and the purchase effort (based on the particular channel) of the product. We use a linear utility function as in Srinivasan (1982) and Vandenbosch and Weinberg (1995). In particular, the customer derives utility $U_{i}=R-E_{i}-P_{i}$ from the product purchased at price $P_{i}$ through channel $i$, with $i \in\{T, W\}$ for the traditional and web channels. $R$ represents the reservation price for the product, $E_{i}$ represents the amount of effort to buy the product in channel $i$ with $E_{i} \sim U n i f\left[0, \alpha_{i}\right]$ and $\alpha_{i}$ is a scaling factor for the channel. We follow the assumptions of Vandenbosch and Weinberg (1995) and assume that $R$ is constant across the population. ${ }^{1}$ Customer effort required for each channel ( $E_{T}$ and $\left.E_{W}\right)$ are independent and uniformly distributed. Heterogeneity of the channels is captured through the scaling factors $\alpha_{T}$ and $\alpha_{W}$, which can be different for the two channels and are assumed to be strictly greater than zero.

\footnotetext{
${ }^{1}$ A more complex rendering of this model might assume that $R$ varies across the population. Then the net utility would require the evaluation of the sum of the two random variables: effort and reservation prices. If this convolution was uniformly distributed, the resulting model would be equivalent to the current model.
} 
Our model builds on the familiar linear Hotelling (1929) model and captures not only market share but also market penetration. In our model the market potential is fixed, but market penetration depends on price. Thus, demand is elastic and prices can be used to influence not only the relative market shares, but also the percentage of the market that purchases a product. We model both market share and market penetration by assuming that $R$ is sufficiently low so that not all customers participate. (See Appendix for conditions on $\mathrm{R}$ that are sufficient for this assumption to hold.) This is in contrast to the models in many of the related works, where full market coverage is assumed. In our model, customers will purchase the product only if the net utility from at least one channel is positive. If both channels provide positive utility, the customer will buy from the higher-utility channel. The retailer's decision is retail price $P_{T}$ while the manufacturer chooses both a wholesale price $B$ to charge the retailer as well as the web retail price $P_{W}$. We first consider the case where the manufacturer commits to matching the traditional channel retail price in the direct channel in order to mitigate channel conflict (i.e., $P_{T}=P_{W}=P$ ). We analyze the relaxation of this constraint in section 4.2.

The efforts for the two channels for a specific customer $\left(E_{T}\right.$ and $\left.E_{W}\right)$ can be compared directly; the smaller of the two corresponds to the channel that is more convenient for that customer. The effort consumers require in the traditional channel may be thought of as their distance from the retail store. The effort consumers require in the web channel may be thought of as the accessibility and comfort related to buying via the web. Consumers with a low web effort may be thought of as experienced web users who value the convenience of e-tailing, whereas those with a high web effort may not have convenient web access and/or may be concerned about the security of conducting financial transactions over the Internet. We assume that the web effort and traditional effort are independent.

Additional costs to the consumers, such as taxes, shipping or handling costs, could lead to higher "net" retail prices in the two channels. However, our observation is that firms frequently match prices prior to these costs (see examples in Table 1). While such costs could be incorporated into our model by adjusting the respective channel prices or efforts, it would be at the expense of tractability and clarity. Also note that these costs in practice might roughly offset each other: the full price the customer will pay in the direct channel may include shipping and handling, while the full price in the traditional channel may include taxes. 
The relative values of $\alpha_{T}$ and $\alpha_{W}$ are used to represent different types of populations. Let $\gamma$ be the ratio of the scaling factors, i.e., $\gamma=\alpha_{W} / \alpha_{T}$. When $\gamma>1$, the population requires less effort on average to purchase from a traditional channel versus the web. One might expect that $\gamma$ is relatively high for the (relatively new) web channel but will decrease over time for a particular product as the population in general becomes more comfortable purchasing products over the Internet. We later demonstrate that the equalpricing policy may be reasonable for profit maximizing manufacturers when $\gamma$ is large but less reasonable as $\gamma$ declines.

Without loss of generality we assume that the market size is one. We let $C_{T}$ denote the channel cost per unit that the retailer incurs in selling in the traditional channel and $C_{W}$ denote the channel cost per unit that the manufacturer incurs in selling in the Internet channel. We assume that manufacturing costs are zero, although all our analytical findings carry through for the case with non-zero manufacturing cost, with appropriate adjustments to the specific threshold values.

Demand curves are determined as follows. Consider first the traditional channel with a manufacturer and a retailer, prior to the manufacturer's introduction of an Internet channel. The manufacturer is a Stackelberg leader who sets her wholesale price knowing how the retailer will respond. In particular, it costs the retailer $B+C_{T}$ to stock and sell a unit to a customer at price $P_{T}$. As described above, the traditional channel faces demand based on the customer's distance from the retailer. The probability that a randomly selected customer will purchase the product provides a downward sloping demand curve:

$\operatorname{Pr}\{$ a customer will buy $\}=\operatorname{Pr}\left\{U_{T}>0\right\}=\operatorname{Pr}\left\{R-P_{T}-E_{T}>0\right\}=\operatorname{Pr}\left\{E_{T}<\left(R-P_{T}\right)\right\}=\left(R-P_{T}\right) / \alpha_{T}$.

The traditional retailer chooses a price $P_{T}$ to maximize his expected profit $\Pi_{R}$ : $\Pi_{R}\left(P_{T}\right)=\left(\left(R-P_{T}\right) / \alpha_{T}\right)\left(P_{T}-B-C_{T}\right)$.

Next consider the addition of an Internet channel. We must now account for effort in the web channel as well as the effort in the traditional channel. If utility is positive from at least one channel, the customer will purchase the product from the channel that provides the greatest utility. If neither channel provides positive utility, the customer elects not to purchase a product. Expected profit is calculated over the 
appropriate regions of the joint distribution of $E_{T}$ and $E_{W}$, the random variables for scaled traditional and web effort, respectively. For the analysis that follows, we consider the case that the manufacturer commits to matching prices in the two channels, i.e., $P_{T}=P_{W}=P$. (We consider the relaxation of this constraint in section 4.2.) Figure 1 illustrates the case where the population requires more effort on average to purchase from the web channel, i.e., $\gamma>1$.

Figure 1: Customer Channel Preference Based on Scaled Effort

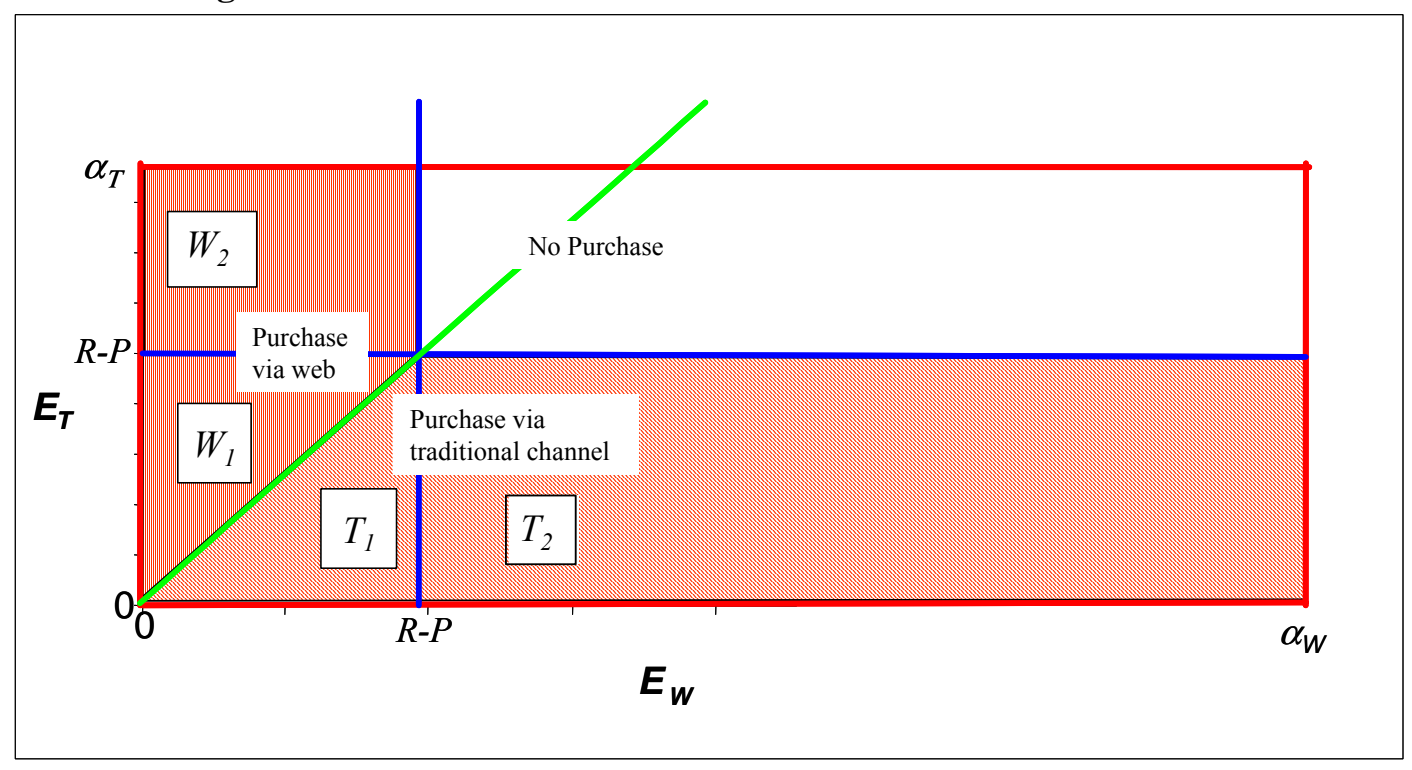

While the channel preference is determined by the customer's position relative to the 45 degree indifference line, the purchase decision depends on the interplay of both effort and price, i.e., it depends on the net utility that a customer can receive by purchasing a product from the preferred channel. In particular, for a given set of prices, customers with low effort in the traditional channel (e.g., they live close to the store) or low effort in the web channel (e.g., they find the web convenient) are relatively more likely to buy the product, while customers who have high efforts in both channels are less likely to purchase the product.

Prices above $R$ provide positive utility to $0 \%$ of the population while prices below $R-\alpha_{i}$ provide positive utility to $100 \%$ of the population. We focus on retail prices that satisfy $R-\alpha_{i}<P<R$. Utility is greater than zero for all customers whose web effort $E_{W} \leq(R-P)$ (regions $W_{2}, W_{l}$, and $T_{l}$ of Figure 1) and 
for all customers whose traditional effort $E_{T} \leq(R-P)$ (regions $W_{1}, T_{1}$, and $T_{2}$ ). Customers in region $W_{2}$ are new customers generated through the addition of the web channel. Customers in regions $W_{1}$ and $T_{1}$ receive positive utility from both channels. Customers in region $W_{l}$, above the diagonal line $E_{T}=E_{W}$, have a preference for the web channel, while those in region $T_{1}$ have a preference for the traditional channel. For a given set of parameter values and prices, the fraction of customers in each region is calculated from the effort distributions as follows:

$W_{2}=\operatorname{Pr}\{$ Customer buys via web but would not buy from traditional channel $\}=\left(1-\frac{R-P}{\alpha_{T}}\right)\left(\frac{R-P}{\alpha_{W}}\right)$,

$W_{I}=\operatorname{Pr}\{$ Customer would buy from either channel but prefers web $\}=\frac{1}{2 \alpha_{T} \alpha_{W}}(R-P)^{2}$, and

$T=T_{1}+T_{2}=\operatorname{Pr}\{$ Customer buys from traditional channel $\}=\left(\frac{R-P}{\alpha_{T}}\right)-W_{1}$.

\subsection{Base Case: A Single Channel}

In this section we determine optimal wholesale and retail prices for the traditional channel prior to the introduction of the Internet channel for comparison as a base case, and we use the subscript $b$ to identify prices and resulting profits for this case. It is easy to show that, given any wholesale price $B_{b}$, the retailer's profit maximizing retail price is $P_{b}{ }^{*}\left(B_{b}\right)=\left(R+C_{T}+B_{b}\right) / 2$.

Given that she knows how the retailer will respond, the manufacturer chooses the profit-maximizing wholesale price $B_{b}{ }^{*}=\left(R-C_{T}\right) / 2$, leading to the base case retail price $P_{b}{ }^{*}=\left(3 R+C_{T}\right) / 4$. Resulting expected profits in the base case are $\Pi_{b M}^{*}=\left(R-C_{T}\right)^{2} /\left(8 \alpha_{T}\right)$ for the manufacturer and $\Pi_{b R}^{*}=\left(R-C_{T}\right)^{2} /\left(16 \alpha_{T}\right)$ for the retailer.

As a point of reference, if the channels were centrally owned, expected supply chain profits would be $\left(R-C_{T}\right)^{2} /\left(4 \alpha_{T}\right)$. Thus the effect of double-marginalization is a reduction in expected supply chain profits of $\left(R-C_{T}\right)^{2} /\left(16 \alpha_{T}\right)$. 


\subsection{Manufacturer Adds a Direct Channel While Ensuring Prices in the Direct Channel Match Prices in the Traditional Channel}

In this section, we analyze the effect of the manufacturer's introduction of an Internet-based channel on the supply chain. A naïve strategy for both the manufacturer and the retailer would be to continue to use wholesale and retail prices as in the base case. While we suspect that the naïve strategy is used at least occasionally in practice, it is clearly suboptimal. Thus here we assume that the manufacturer, as a Stackelberg leader, updates her wholesale price knowing how the retailer responds given the supply chain structure with its two channels. We consider three strategies for the manufacturer, each of which assumes that the manufacturer, in order to minimize channel conflict, commits to setting prices in the Internet channel to match prices in the traditional channel.

The sequence of events is as follows. First, the manufacturer maximizes her profits $\Pi_{M}(B)=(B)\left(T_{1}+T_{2}\right)+\left(P^{*}(B)-C_{W}\right)\left(W_{1}+W_{2}\right)$ by determining her optimal wholesale price. As Stackelberg leader she knows how the retailer will respond in setting his retail price given her choice of wholesale price. Next, the retailer determines an optimal retail price to maximize his profits $\Pi_{R}(P)=\left(P-B-C_{T}\right)\left(T_{1}+T_{2}\right)$. In doing so, the retailer assumes that the manufacturer will match in the direct channel whatever retail price the retailer chooses for the traditional retail channel. The resulting optimal retail price $P^{*}(B)$ will be a function of the wholesale price $B$.

In the first strategy we consider, the manufacturer keeps the wholesale price as it was prior to the introduction of the Internet channel and for the retail price uses the price that the retailer will choose given the presence of the new channel. In the second strategy, the manufacturer sets the wholesale price at the appropriate level so that the retailer keeps the retail price as it was prior to the introduction of the direct channel. In the third strategy, the manufacturer sets the wholesale price in order to maximize her profit, with no consideration of maintaining base retail or wholesale prices, although she commits to using the retail price that the retailer will choose. After the discussion of these three strategies, in the next section we explore the effects of the different strategies on supply chain performance. 


\subsubsection{Strategy 1: Wholesale Prices are Kept as Before}

In order to minimize disruption to the relationship with the retailer, in addition to a policy of matching the retailer's price, the manufacturer introduces the new channel while keeping the base case wholesale price. This strategy represents a policy for the manufacturer that nominally does not change the relationship with the retailer, who buys the products from the manufacturer at the same wholesale price as before. However, the retailer responds to the changed marketplace by adjusting his price to account for the presence of the new channel. While this is clearly a non-optimal strategy for the manufacturer, it might be perceived as a useful strategy to introduce the new channel with less channel conflict, and we will see that it may increase her profits compared to the base case. Theorem 1 highlights how the resulting prices and profits compare to those in the base case. For this wholesale-unchanged strategy we use a subscript 1 for prices and profits and a superscript (1) for threshold values. All proofs are provided in the Appendix.

\section{Theorem 1}

Let $P_{1} *$ be the optimal price for the retailer in Strategy 1 , and $\bar{C}_{W}{ }^{(1)}$ be a threshold (defined in the Appendix). Then, within our region of interest $\left(R-\alpha_{i}<P<R\right)$,

$$
\begin{array}{ll}
\text { i) } & P_{I}^{*}>P_{b}{ }^{*}, \\
\text { ii) } & \Pi_{1 R}^{*}<\Pi_{b R}^{*} \text {, and } \\
\text { iii) } \quad \Pi_{1 M}^{*}>\Pi_{b M}^{*} \text { iff } C_{W}<\bar{C}_{W}{ }^{(1)} .
\end{array}
$$

Theorem 1 shows that if a new channel is introduced by the manufacturer, and she makes no adjustment to wholesale prices, then there is upward pressure on retail prices. Although the retailer faces increased competition (compared to the monopoly position of the base case), the competition effect is more than offset by the ability of the players to segment the market. With the addition of a new channel, some customers who were at a relatively far distance from the traditional channel will find the new channel to be convenient and will be willing to pay a higher price. It becomes worthwhile for the retailer to increase prices, extracting surplus from those customers relatively close to the retailer. However, the retailer's higher margins are more than offset by decreased sales in the traditional channel which loses market share to the 
new channel, and the retailer's expected profits always decline. The manufacturer is constrained by equal prices in the choice of a retail price and by the choice to not optimize the wholesale price. In this relatively passive strategy the manufacturer benefits only if her costs are sufficiently low such that the web sales are sufficiently profitable to offset reduced sales in the traditional channel (which remain at the base level margin). In the end, the retailer is worse off in spite of the manufacturer's efforts to minimize channel conflict by maintaining the base wholesale price.

\subsubsection{Strategy 2: Retail Prices are Kept as Before}

Another strategy to minimize the disruption to the supply chain is to ensure that retail prices remain unchanged with the introduction of the new channel. For this to occur, the manufacturer sets the wholesale price in such a way that the retailer will have an incentive to keep retail prices fixed at the base case level. While this is also clearly a non-optimal strategy for the manufacturer, we will see that it can increase profits compared to the base case and that it improves the retailer's profits. Theorem 2 highlights how the resulting prices and profits compare to those of the base case, using a subscript 2 and superscript (2) for this case with unchanged retail price.

\section{Theorem 2}

Let $B_{2}{ }^{*}$ be the wholesale price for the manufacturer in Strategy 2 and $\bar{C}_{W}{ }^{(2)}$ be a threshold value (defined in the Appendix). Then, within our region of interest $\left(R-\alpha_{i}<P<R\right)$,

i) $\quad B_{2}^{*}<B_{b} *$,

ii) $\quad \Pi_{2 R} *>\Pi_{b R} *$, and

iii) $\quad \Pi_{2 M} *>\Pi_{b M} *$, iff $C_{W}<\bar{C}_{W}^{(2)}$.

Theorem 2 shows that if a new channel is introduced by the manufacturer, and she sets the wholesale price so that retail prices will remain unchanged, then this wholesale price will be lower than the wholesale 
price prior to the new channel. ${ }^{2}$ This strategy also results in the retailer having higher expected profits, while the manufacturer experiences higher expected profits if and only if the costs in the new channel are sufficiently low. The introduction of the new channel (while maintaining the original retail price) creates benefit to customers with a low web effort. All of the original customers continue to buy (since the retail price is unchanged), but market penetration is increased with the addition of customers who did not buy in the traditional channel but now participate in the new channel. Meanwhile, the reduction in the wholesale price more than compensates the retailer for the loss of those customers who were willing to buy in the traditional channel but now switch to the direct channel. With the introduction of a direct channel, the manufacturer segments the customer base into the direct channel where there is no double marginalization and the traditional channel. The manufacturer must lower the wholesale price in order to ensure that the retailer chooses the retail price that will work well for the manufacturer in the direct channel. The pricematching commitment thus serves to partially coordinate the channels.

It is interesting to note that in Strategy 2 the threshold $\bar{C}_{W}{ }^{(2)}$ is increasing in $\gamma$ :

\section{Corollary 1}

$\partial \bar{C}_{W}^{(2)} / \partial \gamma>0$.

When the Internet channel is relatively less convenient than the traditional channel, a manufacturer can introduce this direct channel and experience increased profits even if the new channel's costs are high. When the Internet channel is relatively more convenient, the new channel's costs must be lower than a reduced threshold compared to the high $\gamma$ case. This result arises in Strategy 2 where the market price is unchanged (by assumption) because with higher values of $\gamma$ the loss in the traditional channel volume decreases, the wholesale price increases (in particular, it approaches $B_{b}$ ), the market share of the Internet channel decreases, and the result is a decrease in the effect of the Internet-channel costs $\bar{C}_{W}{ }^{(2)}$. With higher

\footnotetext{
${ }^{2}$ A lower wholesale price also arises in the similar supply chains, but different models of Chiang et al. (2003) and Tsay and Agrawal (2004b).
} 
values of $\gamma$, most profits come from sales through the traditional channel and so the manufacturer's profits might increase even if Internet-channel costs $\bar{C}_{W}{ }^{(2)}$ are high.

\subsubsection{Strategy 3: Manufacturer Chooses Wholesale Price to Maximize Profit}

We next consider a strategy where the manufacturer more aggressively influences prices in the supply chain. Although we still assume that the manufacturer will match the price that the retailer offers, under this strategy she optimizes her profits by choosing the wholesale price without worrying that the resulting wholesale and retail prices might vary from where they were before she considered selling directly to customers. By allowing both the wholesale price and the retail price to vary, the manufacturer's profits will be greater than in any of the strategies analyzed thus far. The effect on prices, retailer profits, and total supply chain profits, however, is much less obvious.

We use a subscript 3 to indicate this manufacturer-focused strategy. Given that the manufacturer matches the price that the retailer offers to the customer, the only variable directly under her control is the wholesale price, $B_{3}$, to be charged to the retailer. In selecting the wholesale price, the manufacturer fully considers the effect that $B_{3}$ will have on the price to the customers, $P_{3}$, chosen by the retailer, which in turn affects the profits the manufacturer is able to garner in the Internet channel. The retailer selects $P_{3}$ to maximize his profits, $\Pi_{3 R}$, which equal the margin on each unit sold, multiplied by his market share:

$$
\Pi_{3 R}=\left(P_{3}-B_{3}-C_{T}\right)\left(\frac{R-P_{3}}{\alpha_{T}}-\frac{\left(R-P_{3}\right)^{2}}{2 \alpha_{T} \alpha_{W}}\right) .
$$

The retailer's profit equation (2) can be used to determine the optimal price chosen by the retailer as a function of the wholesale price $B_{3}$.

$$
P_{3}^{*}=\frac{1}{3}\left(2 R+B_{3}+C_{T}-2 \alpha_{W}+\sqrt{\left(C_{T}+B_{3}-R\right)^{2}+2 \alpha_{W}\left(C_{T}+B_{3}-R\right)+4 \alpha_{W}^{2}}\right) .
$$

The manufacturer can use the retailer's response function (3) to derive an equation for her own profits as a function of $B_{3}$ (and not $P_{3}$ ), which lets her determine the value of $B_{3}$ that will maximize her profits. Closed form expressions for both the manufacturer's profit and the optimal wholesale price can be derived, but these 
expressions are not reported here as they are quite complex. However, we use them in a computational study, and represent and discuss the results in Section 4.

\subsection{A Centralized Supply Chain Using a Traditional and Direct Channel}

For comparison, in this section we determine the maximum profits that the supply chain could achieve given the same retail price in both channels (i.e., the supply chain profits achievable under centralization). We use a subscript $c$ and superscript (c) to refer to this case.

In the centralized scenario, the wholesale price merely represents an internal transfer payment and hence has no impact on the optimal decisions and resulting system wide profit. Expressions for the resulting optimal price $P_{c}^{*}$ and the expected profits $\Pi_{c} *$ are given in the appendix. The following relationship holds for the centralized solution:

\section{Theorem 3}

$$
P_{c}^{*}<P_{b}^{*} \text { iff } C_{W}<\bar{C}_{W}{ }^{(c)} .
$$

As long as the costs in the new channel are sufficiently low, the retail price in the centralized supply chain will be lower than the base case price. Interestingly, if web channel costs are sufficiently high, the retail price that maximizes supply chain profits exceeds the base case retail price, even though double marginalization is eliminated. Other things being equal, higher web-channel costs reduce the average profitability of sales over the two channels. Given this lower average margin, reducing the retail price to increase sales volume through price reductions becomes less profitable to the central planner.

We note that even if there is no centralized decision maker, by anticipating the optimal response of the retailer, the manufacturer could induce the centralized solution by selecting the wholesale price that leads to $P_{c}{ }^{*}$ and $\Pi_{c} *$, thereby coordinating the supply chain. However, the manufacturer's profits would be sharply lower under such a strategy, so the manufacturer would not be willing to coordinate the channel without inducement. 


\section{Computational Studies}

In this section we use computational studies to explore the effect of channel convenience and costs on profits and prices at the retailer and at the manufacturer. In Section 4.1 we compare the performance of the different strategies across various scenarios with a focus on the impact of web channel convenience, while in Section 4.2 we consider the effect of the manufacturer's commitment to equal pricing. Consistent with our focus on the issues surrounding the implementation of a direct channel that competes with the traditional channel, our numerical study includes a broad range of parameter values where the manufacturer's profitability is increased by opening the direct channel, and she therefore chooses to compete with the traditional channel.

\subsection{Impact of web channel convenience}

We use a full factorial experiment with $\alpha_{T} \in\{6,9,12\}, C_{W} \in\{2,3,4\}, C_{T} \in\{2,3,4\}$ and $R \in\{6,9,12\}$ first along with high values of $\gamma \in\{20,40,60\}$ and then with moderate values of $\gamma \in\{2 / 3,1$, $4 / 3\}$. In the following, we present the average outcomes across the 243 cases with high and moderate values of $\gamma$, respectively. We focus on high and moderate values of $\gamma$, corresponding most closely to our belief of current and near future conditions in most product categories.

A comparison of the equilibrium outcomes under the different strategies for high values of $\gamma$ is provided in Table 2. As benchmarks, in addition to the base case, we include the decisions and the performance of a centralized system as well as those of what we call the naïve case (i.e., the introduction of a direct channel with both the same wholesale price and the same retail price as in the base case). For ease of comparison, we normalize base-case outcomes to 100 .

\begin{tabular}{|c|c|c|c|c|c|c|}
\hline & Base Case & $\begin{array}{c}\text { Naïve Case } \\
\text { 2 channels }\end{array}$ & $\begin{array}{c}\text { Strategy } \\
\mathbf{1}\end{array}$ & $\begin{array}{c}\text { Strategy } \\
\mathbf{2}\end{array}$ & $\begin{array}{c}\text { Strategy } \\
\mathbf{3}\end{array}$ & $\begin{array}{c}\text { Centralized } \\
\text { 2 channels }\end{array}$ \\
\hline Manufacturer Profits & 100 & 101.9 & 104.0 & 104.0 & 104.0 & $\mathrm{n} / \mathrm{a}$ \\
\hline Retailer Profits & 100 & 99.7 & 99.7 & 100.0 & 101.9 & $\mathrm{n} / \mathrm{a}$ \\
\hline Supply Chain Profits & 100 & 101.2 & 102.6 & 102.7 & 103.3 & 136.3 \\
\hline Wholesale Price & 100 & 100.0 & 100.0 & 99.9 & 98.9 & $\mathrm{n} / \mathrm{a}$ \\
\hline Retail Price $\left(\boldsymbol{P}_{\boldsymbol{T}}=\boldsymbol{P}_{\boldsymbol{w}}\right)$ & 100 & 100.0 & 100.0 & 100.0 & 99.9 & 81.0 \\
\hline
\end{tabular}

Table 2: Average Results for High Values of Gamma 
From our experiments we see that the addition of an inconvenient direct channel has only a marginal impact on manufacturer and retailer profits, and the resulting adjustments in the wholesale price by the manufacturer and/or in the retail price by the retailer are minor. The negative implications of double marginalization in this setting are clear, as prices are substantially higher than the optimal price set by a centralized firm, and supply chain profits are about $24 \%$ below what could be achieved through coordination. While the manufacturer is, on average, indifferent between the three strategies, the retailer prefers Strategy 3.

\begin{tabular}{|c|c|c|c|c|c|c|}
\hline & Base Case & $\begin{array}{c}\text { Naïve Case } \\
\mathbf{2} \text { channels }\end{array}$ & $\begin{array}{c}\text { Strategy } \\
\mathbf{1}\end{array}$ & $\begin{array}{c}\text { Strategy } \\
\mathbf{2}\end{array}$ & $\begin{array}{c}\text { Strategy } \\
\mathbf{3}\end{array}$ & $\begin{array}{c}\text { Centralized } \\
\mathbf{2} \text { channels }\end{array}$ \\
\hline Traditional Channel & $18.1 \%$ & $18.0 \%$ & $18.0 \%$ & $18.0 \%$ & $18.1 \%$ & $35.6 \%$ \\
\hline Web Channel & $\mathrm{n} / \mathrm{a}$ & $0.5 \%$ & $0.5 \%$ & $0.5 \%$ & $0.5 \%$ & $0.8 \%$ \\
\hline Total & $18.1 \%$ & $18.5 \%$ & $18.4 \%$ & $18.5 \%$ & $18.6 \%$ & $36.5 \%$ \\
\hline
\end{tabular}

Table 3: Average Demands for High Values of Gamma

Table 3 illustrates how the introduction of the direct channel and the chosen manufacturer strategy affect demands on the two channels as well as total market penetration by providing average demands in each channel (as a percent of the market) in the experimental results. The results for the scenarios with a relatively inconvenient web channel elucidate why the introduction of the direct channel in those setting does not have any sizable effect on either party's profit: given their extreme preference for the traditional channel, customers virtually ignore the new channel, which cannot capture any meaningful market share, even under centralization.

\begin{tabular}{|c|c|c|c|c|c|c|}
\hline & Base Case & $\begin{array}{c}\text { Naïve Case } \\
\text { 2 channels }\end{array}$ & $\begin{array}{c}\text { Strategy } \\
\mathbf{1}\end{array}$ & $\begin{array}{c}\text { Strategy } \\
\mathbf{2}\end{array}$ & $\begin{array}{c}\text { Strategy } \\
\mathbf{3}\end{array}$ & $\begin{array}{c}\text { Centralized } \\
\text { 2 channels }\end{array}$ \\
\hline Manufacturer Profits & 100 & 167.1 & 237.0 & 240.1 & 254.0 & $\mathrm{n} / \mathrm{a}$ \\
\hline Retailer Profits & 100 & 90.2 & 90.6 & 102.2 & 149.6 & $\mathrm{n} / \mathrm{a}$ \\
\hline Supply Chain Profits & 100 & 141.4 & 188.2 & 194.1 & 219.2 & 245.0 \\
\hline Wholesale Price & 100 & 100.0 & 100.0 & 92.9 & 71.9 & $\mathrm{n} / \mathrm{a}$ \\
\hline Retail Price $\left(\boldsymbol{P}_{\boldsymbol{T}}=\boldsymbol{P}_{\boldsymbol{w}}\right)$ & 100 & 100.0 & 101.2 & 100.0 & 97.1 & 85.6 \\
\hline
\end{tabular}

Table 4: Average Results for Moderate Values of Gamma

Table 4 illustrates the corresponding results for the scenarios with moderate values of $\gamma$ (i.e., for those cases where the convenience of direct channel is comparable to that of the traditional channel). When the direct channel effort is comparable to the traditional channel, the introduction of such a channel and particularly the manufacturer's strategy vastly affect the performance of the manufacturer, the retailer, and 
the entire supply chain. Manufacturer profits increase substantially even under the naïve strategy. Under the three conscious strategies, manufacturer profits are more than doubled on average, as she does not have to split profits with any channel partner in the direct channel, and market penetration increases dramatically (see Table 5 below). Under the optimal price-matching strategy from a manufacturer's perspective (Strategy 3), profits increase by more than $150 \%$ after the introduction of the direct channel, even though this channel is identical to the traditional channel in terms of both average convenience and average channel cost. Retailer profits increase due to the sharp decline in the wholesale price which more than compensates for the slight decrease in demand (lost to the web channel) and the small decline in the retail price.

\begin{tabular}{|c|c|c|c|c|c|c|}
\hline & Base Case & $\begin{array}{c}\text { Naïve Case } \\
\mathbf{2} \text { channels }\end{array}$ & $\begin{array}{c}\text { Strategy } \\
\mathbf{1}\end{array}$ & $\begin{array}{c}\text { Strategy } \\
\mathbf{2}\end{array}$ & $\begin{array}{c}\text { Strategy } \\
\mathbf{3}\end{array}$ & $\begin{array}{c}\text { Centralized } \\
\mathbf{2} \text { channels }\end{array}$ \\
\hline Traditional Channel & $18.1 \%$ & $15.8 \%$ & $14.9 \%$ & $15.8 \%$ & $17.6 \%$ & $24.8 \%$ \\
\hline Web Channel & $\mathrm{n} / \mathrm{a}$ & $17.3 \%$ & $16.2 \%$ & $17.3 \%$ & $19.3 \%$ & $27.1 \%$ \\
\hline Total & $18.1 \%$ & $33.1 \%$ & $31.0 \%$ & $33.1 \%$ & $36.9 \%$ & $51.9 \%$ \\
\hline
\end{tabular}

Table 5: Average Demands for Moderate Values of Gamma

For moderate values of $\gamma$, Table 5 demonstrates that the direct channel introduction substantially increases total market penetration, although falling short of achieving the sales volume of a centralized firm. The new web channel is the clear source of this increase as average sales through the traditional channel are reduced under all strategies. Consequently, the retailer can only be compensated through increased unit margins. We further see that the lower retail price under Strategy 3 mitigates the cannibalization caused by the web channel, but still, on average, fails to maintain pre-direct channel sales volume on the traditional channel. With the introduction of a comparably convenient direct channel, the manufacturer and retailer are able to segment the market so that a higher percentage of the market will purchase the product, with each consumer buying from the most convenient channel.

The introduction of a direct channel can harm or benefit the retailer. Surprisingly, the retailer prefers the scenario where the manufacturer acts optimally in terms of her own objectives. While average retailer profits decrease notably under the naïve strategy and under Strategy 1, they increase slightly under Strategy 2 and grow substantially if the manufacturer follows Strategy 3. The objectives of the manufacturer and the retailer are connected through the manufacturer's commitment to matching the retail price set by the retailer 
in the traditional channel. If free to set a different price on the web channel, the manufacturer would almost always want to price much lower on the web channel. (See the results in the following section.) Given the constraint to price-matching, the only way to achieve a lower retail price is by granting the retailer a wholesale price reduction, which is the source of the retailer's relative well being under Strategy 3. Compared to the substantial wholesale price reduction under Strategy 3, the retail price reduction is rather small, leaving the retailer with much improved unit profit margins. Even though the resulting average retail price is still far above the price that would be set by a centralized firm, the resulting supply chain profits are only about $10 \%$ below this benchmark that could theoretically be achieved through perfect coordination.

Of the 243 cases considered in Table 3, retailer profits under Strategy 3 exceed base case profits in all but 25 cases. The 25 cases are characterized either by a significant cost disadvantage of the web-channel $\left(C_{W}=4\right.$ vs. $\left.C_{T}=2\right)$, giving the manufacturer little incentive to strive for sales volume on the web-channel and leading to a higher wholesale price than under the base case, or by settings with a very low effort for using the traditional channel $\left(\alpha_{T}=6.19\right.$ on average $)$ coupled with a high reservation price $(R=11.44$ on average), where a retail price reduction has little effect on the sales volume, but decreases the margin on a significant existing sales volume, leading the retailer to set a higher retail price in spite of a wholesale price reduction. Average retailer loss in these 25 scenarios is $10.3 \%$, compared to an average gain of $58.3 \%$ across the other cases. For high values of $\gamma$, retailer profits decrease in 24 out of 243 cases and these scenarios are characterized in the same way. However, as reflected in Table 2, the introduction of the direct channel in those cases has a much lesser effect and retailer profits in these 24 scenarios are reduced by only $0.5 \%$ on average (compared to an average gain of $2.1 \%$ across the other cases).

Similar results are obtained when comparing Strategy 3 to Strategies 1 and 2. For moderate values of $\gamma$, Strategy 3 results in higher retailer profits than Strategy 2 in all but 32 scenarios (out of 243) and higher retailer profits than Strategy 1 in all but 9 scenarios. End customers are also better off (through lower retail prices) with Strategy 3 in all of the scenarios where retailer profits are higher. For high values of $\gamma$, Strategy 3 is preferred by the retailer and customers over Strategy 2 in all but 24 scenarios and over Strategy 1 in all but 12 scenarios. 
While not shown here, the corresponding results for an experiment with low values of $\gamma \in\{1 / 20$, $1 / 40,1 / 60\}$ demonstrate a similar effect on supply chain profits. The retailer continues to prefer Strategy 3 and the resulting retail price is even lower than for moderate values of $\gamma$.

We further illustrate the effect of the relative web-channel convenience on the manufacturer's and retailer's profits through an example where we vary $\gamma$ (from $2 / 3$ to 30 ) while keeping the other parameters fixed at their mid values, i.e $\alpha_{T}=9, C_{W}=3, C_{T}=3$, and $R=9$. The resulting supply chain profits - the sum of profits to both the retailer (from the traditional channel) and to the manufacturer (from both the traditional and the web channel) - increase with the introduction of a new channel, especially for lower values of $\gamma$ (see the top frame of Figure 2). The new channel provides an opportunity for the supply chain to segment the market, increasing market penetration and/or increasing prices. Compared to the base case (traditional channel only), the dual channel Strategies 1,2, and 3 show a significant increase in supply chain profits for each strategy for lower values of $\gamma$ and a smaller increase for higher values of $\gamma$. In terms of supply chain profits, Strategy 3 slightly outperforms Strategy 2 which outperforms Strategy 1 across all values of $\gamma$.

In this example, which uses parameters that include comparable costs in the two channels, manufacturer and retailer profits each increase marginally with the addition of the direct channel under high values of $\gamma$ for Strategies 2 and 3. Strategy 1 leaves the retailer slightly worse off. (See the middle and lower frames of Figure 2, respectively). Not surprisingly, the manufacturer benefits most when the Internet is relatively convenient - for lower values of $\gamma$, the manufacturer's benefits from the introduction of the direct channel are substantial. It is interesting to note that she is nearly indifferent to Strategies 1, 2, and 3. While not visible in the graph in the middle frame of Figure 2, Strategy 3 marginally outperforms Strategy 2, which marginally outperforms Strategy 1 for the manufacturer across all values of $\gamma$. 
Figure 2: Profits vs. Relative Web Channel Convenience
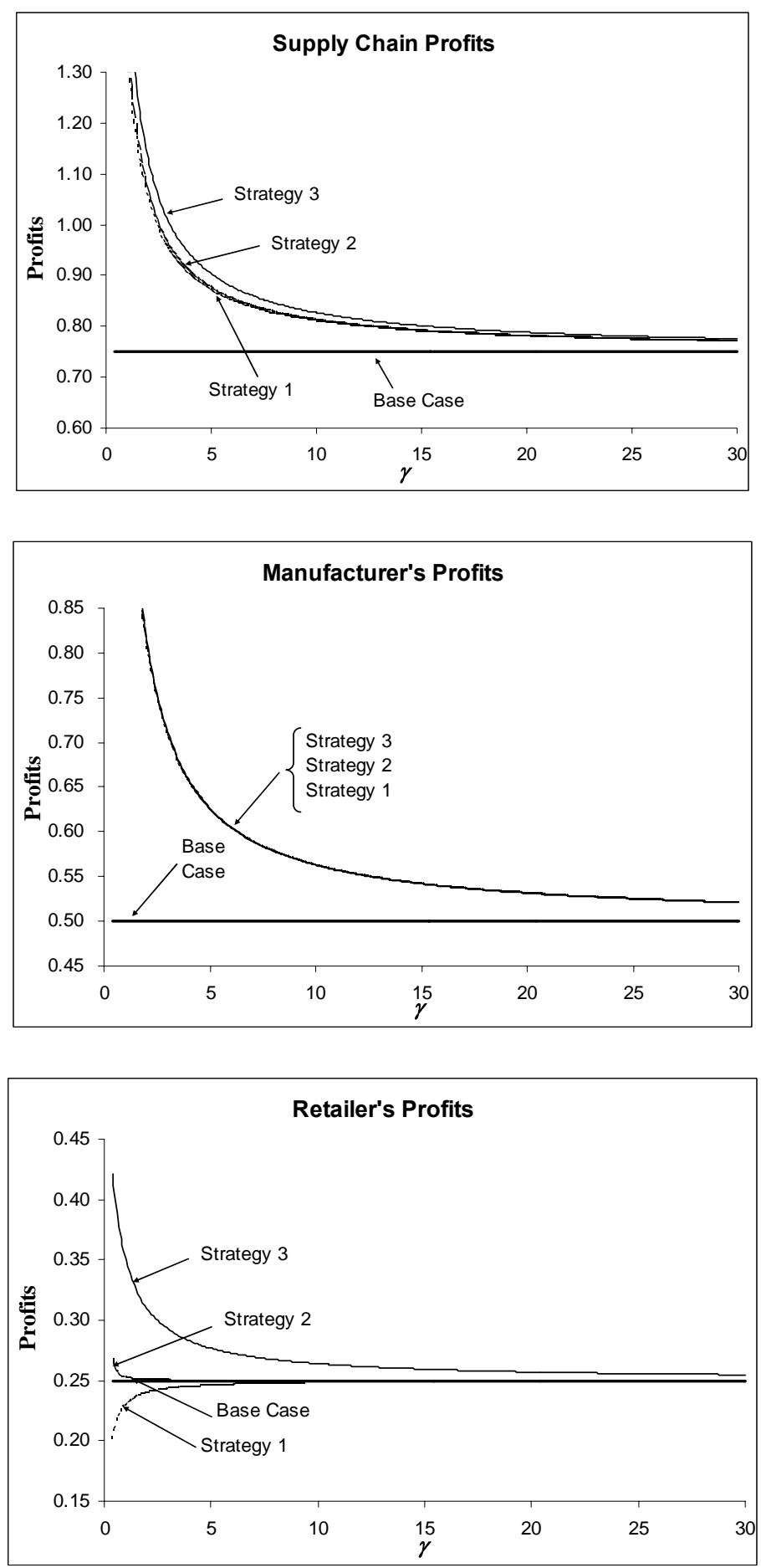

We will see in the next section that for moderate values of $\gamma$, the manufacturer could increase profits even more by not committing to equal prices in the two channels. From the bottom frame of Figure 2 we see that the retailer would prefer the base case over Strategy 1, would benefit slightly from Strategy 2 and 
surprisingly, would prefer that the manufacturer choose Strategy 3. The strategy that maximizes manufacturer profit is also preferred by the retailer. At higher values of $\gamma$ the retailer's profits are fairly insensitive to changes in $\gamma$.

We also observe that as $\gamma$ decreases, the manufacturer captures a greater percentage of the total supply chain profits, capturing the greatest percentage with Strategy 3, followed by Strategy 2, then Strategy 1. If the Internet channel becomes relatively more convenient than the traditional channel, the manufacturer will be able to capitalize by capturing a larger percentage of the profits (which also should be noted is of a larger pie).

In Figure 3 we plot retail prices as a function of $\gamma$. Retail prices are highest in Strategy 1, followed by Strategy 2 (which is also the base-case price) and Strategy 3. We include here, for interest, prices in the centralized scenario. As expected, prices are lowest in the centralized scenario since there is no double marginalization. Under Strategy 1, prices are lower in this example when the Internet is relatively less convenient (high $\gamma$ ). Interestingly, prices under Strategy 3 are higher if the Internet is relatively less convenient. Rather than having to compensate customers for their inconvenience, the manufacturer focuses on segmenting the market and taking advantage of the fact that the web channel is relatively convenient for some customers, even if not convenient for the average customer. At higher levels of inconvenience there is less influence from the direct channel and thus the retail price and market shares remain close to the basecase levels. When the new channel is relatively convenient, the retail price declines and market penetration increases dramatically both from new customers (Region $W_{2}$ of Figure 1) and from lower prices. 
Figure 3: Retail Prices vs. Relative Web Channel Convenience

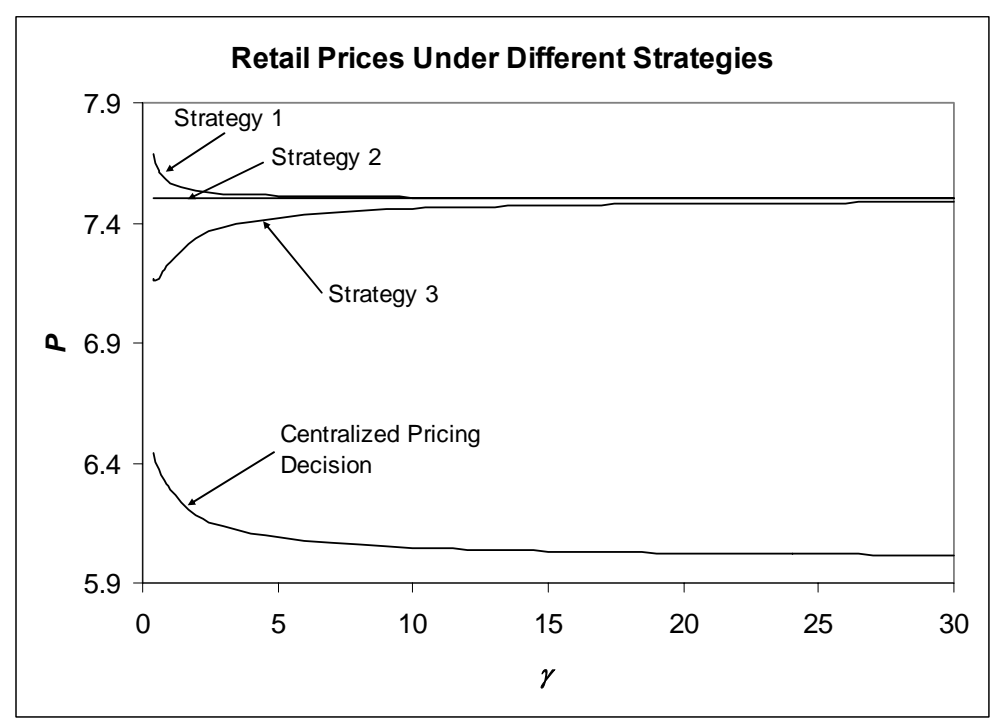

In the example above, we varied $\gamma$ while holding other parameters constant. We are also interested in how the cost in the web channel $C_{W}$ affects supply chain profits, manufacturer profits, and retailer profits.

We find that in all cases of our computational study, the threshold values of $\bar{C}_{W}^{(i)}$ (with $i$ representing Strategy 1 or 2) are above the actual value of $C_{W}$, which implies that manufacturer profits will be higher after the introduction of the direct channel.

Confirming intuition, we find that under all three strategies the increase in manufacturer profits due to the introduction of a new channel strictly increases as the costs of this channel $\left(C_{W}\right)$ decrease. Manufacturer profits increase more quickly as $C_{W}$ decreases, if the traditional channel is very costly. With high costs in the traditional channel, the introduction of a comparatively inexpensive web-channel can substantially reduce the average distribution costs for the supply chain, leading to much improved profitability.

The impact of the new channel introduction on retailer profits under Strategies 1 and 2 is insensitive to web-channel costs, because they play no role in setting wholesale or retail price in these scenarios. However, it is interesting to note that under Strategy 3 the retailer also benefits from lower values of $C_{W}$, which induce the manufacturer to quote a lower wholesale price and thus improve the retailer's profit margin. As discussed above, if web costs are much higher than traditional channel costs, the retailer might 
find Strategy 3 to be less favorable than the base case. Thus, the retailer actually has an interest in the manufacturer achieving low channel costs, as long as the manufacturer commits to equal prices in the two channels. Unfortunately for the retailer, we will see in the next section that if web-channel costs decline, the manufacturer has a strong incentive to abandon the equal-pricing policy.

\subsection{Cost of committing to equal pricing}

The preceding analysis and example assume that the manufacturer credibly commits to match the price set by the retailer. In this section, we explore how the equal-pricing assumption affects supply chain profits by conducting numerical experiments to analyze the impact of the equal-pricing constraint. Through this analysis, we gain some understanding on why a price-matching practice might be widespread, in spite of its non-optimality.

As in the equal-pricing analysis, we consider the manufacturer to be a Stackelberg leader who sets her wholesale price anticipating the second stage pricing game, where both the manufacturer and the retailer simultaneously set their respective retail prices. In this analysis, the manufacturer does not commit to matching the retailer's price but sets a wholesale and a (direct-channel) retail price to optimize her profits across both channels. Neither the manufacturer nor the retailer has an incentive to unilaterally depart from the resulting pure-strategy Nash equilibrium retail prices.

Again, we begin by considering cases where the Internet channel is relatively inconvenient $(\gamma>>1)$. We use the full factorial design for our experiment described in the previous section.

In general, the manufacturer finds it optimal to undercut the retail price quoted by the retailer. Only in 9 of the 243 cases does the manufacturer charge a price in excess of what the retailer charges. All these cases are characterized by a very low reservation price $(R=6)$, and a severe disadvantage of the Internet channel with respect to costs $\left(C_{W}=4\right.$ and $\left.C_{T}=2\right)$.

We find that the manufacturer on average prices $20.1 \%$ below the price quoted by the retailer. However, in spite of this substantial price difference, we find that the average loss in manufacturer profits due to the equal price commitment is only $1.9 \%$. The reason for this small effect on manufacturer profits is the assumed inconvenience of the web channel relative to the traditional channel. Most customers will 
remain with the more convenient traditional channel. Given the relative inconvenience and the resulting small market share for the web channel, the profits generated on the web channel lack the scale to significantly affect overall profits. Hence the manufacturer at this point does not lose much by committing to an equal pricing strategy to mitigate supply chain conflict.

\begin{tabular}{|c|c|c|c|}
\hline & Base Case & $\begin{array}{c}\text { Strategy 3 } \\
\boldsymbol{P}_{\boldsymbol{W}}=\boldsymbol{P}_{\boldsymbol{T}}\end{array}$ & $\begin{array}{c}\text { Manufacturer's Optimal } \\
\text { Allow } \boldsymbol{P}_{\boldsymbol{W}} \neq \boldsymbol{P}_{\boldsymbol{T}}\end{array}$ \\
\hline Manufacturer Profits & 100 & 104.0 & 106.2 \\
\hline Retailer Profits & 100 & 101.9 & 99.1 \\
\hline Supply Chain Profits & 100 & 103.3 & 103.8 \\
\hline Wholesale Price & 100 & 98.9 & 100.1 \\
\hline $\boldsymbol{P}_{\boldsymbol{T}}$ & 100 & 99.9 & 100.0 \\
\hline $\boldsymbol{P}_{\boldsymbol{W}}$ & $\mathrm{n} / \mathrm{a}$ & 99.9 & 83.8 \\
\hline
\end{tabular}

Table 6: Average Results for High Values of Gamma

Table 6 summarizes the results of the numerical study for the high values of $\gamma$, by providing the average results of the study as a percentage of the base case. In particular, it compares the base case (profits and prices prior to the introduction of the direct channel) to the optimal (for the manufacturer) case under equalpricing Strategy 3 (from Table 2), and to the optimal values with no price restriction. Table 6 indicates that the strategy of equal pricing might be reasonable when introducing a direct channel that is relatively inconvenient. If the new channel is at a disadvantage in terms of relative customer preference, committing to matching the retailer's price might mitigate conflict with the traditional channel partner without greatly sacrificing manufacturing profits. (The manufacturer's profit is $104 \%$ of base case on average when it could be $106.2 \%$.) Compared to the optimal strategy, committing to equal prices maintains a higher retail price on the web channel and leaves the retailer with a larger profit margin and on average higher profits.

While perhaps reasonable for the manufacturer to commit to an equal pricing strategy when introducing a new channel that is perceived as much less convenient by the customer, the strategy may later be ill-advised if over time the new channel's average attractiveness increases. The customers' familiarity with the Internet might be expected to grow and the new channel might become better known and relatively more convenient. 
To find insights into this issue, we consider the results of the numerical study where the two channels are more comparable in terms of perceived customer convenience, i.e., $\gamma \in\{2 / 3,1,4 / 3\}$. As before, the manufacturer will find it optimal to undercut the retailer's price in all but 9 cases, which are characterized by a very low reservation price $(R=6)$, and a severe disadvantage of the Internet channel with respect to $\operatorname{costs}\left(C_{W}=4\right.$ and $\left.C_{T}=2\right)$.

We find that once the two channels are of comparable convenience to the customers, the manufacturer has a strong incentive not to match the retailer's price. By undercutting the retailer - the average price difference is $18.8 \%$ - the manufacturer can increase her profits by $17.1 \%$ on average compared to Strategy 3. Table 7 shows the effects of an equal pricing commitment by the manufacturer when $\gamma$ is moderate. (We note that low values of $\gamma \in\{1 / 20,1 / 40,1 / 60\}$ create even stronger incentives for the manufacturer to deviate from equal pricing strategies, with similar results to the retailer.)

\begin{tabular}{|c|c|c|c|}
\hline & Base Case & $\begin{array}{c}\text { Strategy 3 } \\
\boldsymbol{P}_{\boldsymbol{W}}=\boldsymbol{P}_{\boldsymbol{T}}\end{array}$ & $\begin{array}{c}\text { Manufacturer's Optimal } \\
\text { Allow } \boldsymbol{P}_{\boldsymbol{W}} \neq \boldsymbol{P}_{\boldsymbol{T}}\end{array}$ \\
\hline Manufacturer Profits & 100 & 254.0 & 317.4 \\
\hline Retailer Profits & 100 & 149.6 & 66.5 \\
\hline Supply Chain Profits & 100 & 219.2 & 233.7 \\
\hline Wholesale Price & 100 & 71.9 & 107.4 \\
\hline $\boldsymbol{P}_{\boldsymbol{T}}$ & 100 & 97.1 & 100.2 \\
\hline $\boldsymbol{P}_{\boldsymbol{W}}$ & $\mathrm{n} / \mathrm{a}$ & 97.1 & 83.8 \\
\hline
\end{tabular}

Table 7: Average Results for Moderate Values of Gamma

If the web channel becomes more convenient over time, the commitment to equal pricing creates large opportunity costs to the manufacturer and she feels increased pressure to undercut the retailer. In practice, we would expect the occurrence of manufacturers undercutting the retail price of their traditional channel partners to first appear in industries where internet purchases are perceived by customers as being relatively convenient. As mentioned in the introduction, this behavior is now evident in the music and software industries, whose products are frequently easier to sample on-line, and in some instances (product downloads) can be obtained more quickly through the internet channel than by purchasing the product from a traditional retailer. By allowing differential pricing across the two channels and using her advantage as Stackelberg leader, the manufacturer can sharply increase profits to the detriment of the retailer. The retailer 
loses a significant part of his profits due to a sharply increased wholesale price that leads to a drop in the retailer's margin, in spite of the increase of the traditional channel price. Interestingly, the average retail price decreases (in both channels) under Strategy 3 while under the manufacturer's optimal policy retail prices are slightly higher than the base case for the traditional channel but sharply lower in the web channel. Web customers benefit not only from potentially lower effort (if they find the web channel convenient) but also from sharply lower prices in the web channel.

\section{Figure 4 : Effect of Equal-Pricing Strategy on Manufacturer's and Retailer's Profits}
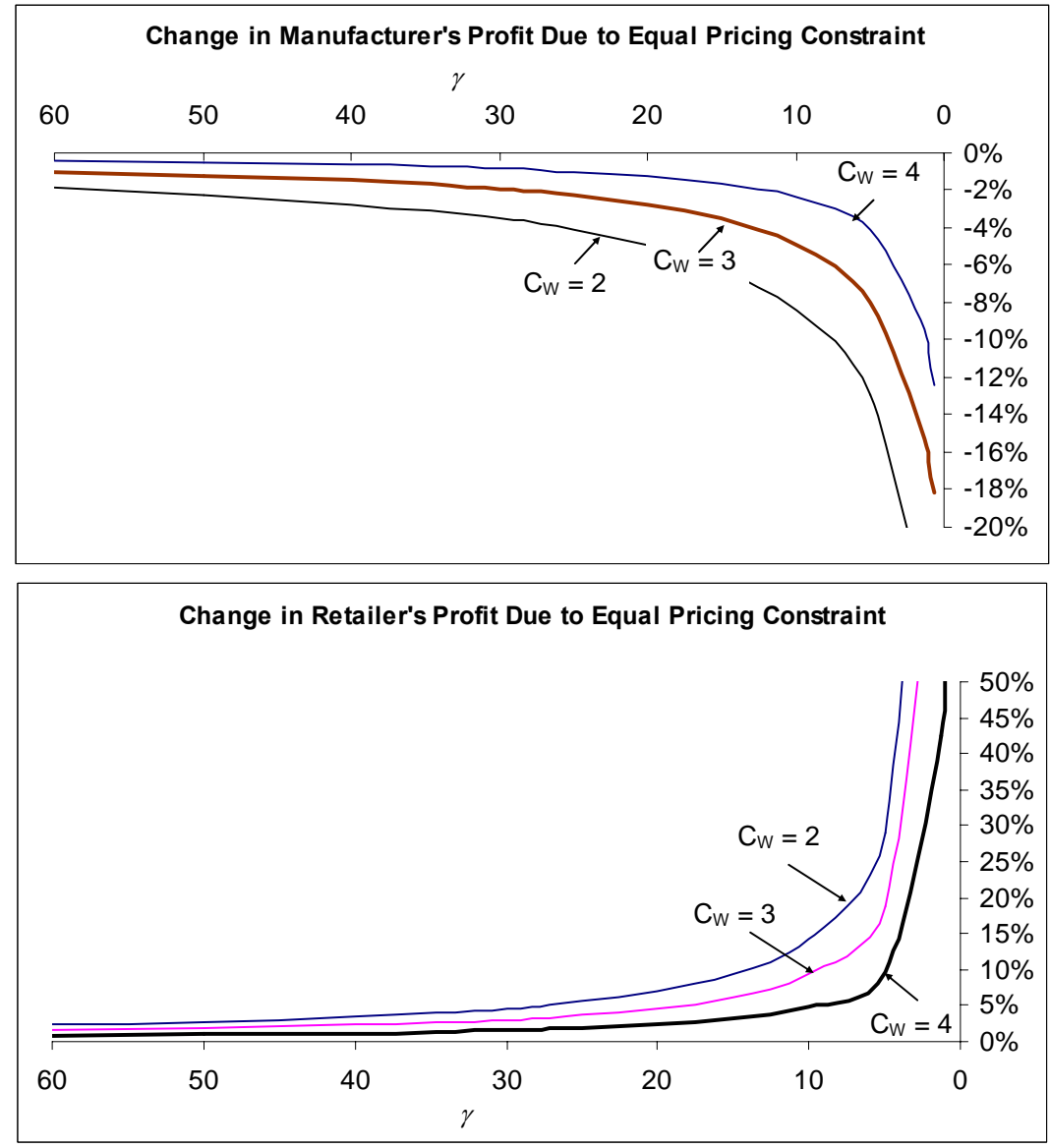

Figure 4 shows the change in manufacturer's profit if she compares the equal-price-constrained case versus her unconstrained optimal case. For high values of $\gamma$ and high values of $C_{W}$, the manufacturer is relatively indifferent to a policy of equal prices across the new and existing channels. In particular, relaxing the policy to permit different prices in the two channels would increase the manufacturer's profits by only 
about $1 \%$ for the highest value of $\gamma$ combined with the highest web cost. At the same time, the retailer's profits would decrease by about $1 \%$. For lower values of $\gamma$ and/or lower values of $C_{W}$, the incentive for the manufacturer to abandon the equal-pricing policy can be quite significant. If the web channel is nearly as convenient on average as the traditional channel, an equal-pricing policy could lead to a reduction in expected profits for the manufacturer of $20 \%$ or more compared to a policy that allows the prices to differ in the two channels.

Comparing the individual scenarios, we find that the benefit of undercutting is consistent across all parameter values other than $\gamma$ and $C_{W}$. It is mainly the relative efficiencies of the two channels in terms of cost and convenience that determine what additional profits the manufacturer can make by undercutting the retailer's price. The potential benefit from undercutting the retailer's price increases if the costs on the Internet channel are low relative to the costs on the traditional channel or if the Internet channel is more convenient than the traditional channel. On the other hand, matching prices might be a tolerable strategy if the Internet is not perceived by the customers to be convenient and/or has channel costs that are not competitive. Hence a strategy with commitment to price matching might be a viable option for a manufacturer that introduces a new channel with an initially substantive cost or convenience disadvantage. The promise of price matching (or the promise not to undercut) is likely to help mitigate conflicts with the traditional channel. We conjecture that price matching is so popular in practice because it reduces channel conflict without being terribly costly while the direct channel is relatively new.

\section{Conclusions}

As manufacturers complement traditional channels with the addition of Internet channels, they should anticipate the effects of the new channel on existing channel relationships. The effect of the manufacturer's pricing decisions on the resulting market share and profitability for the manufacturer and the retailer can be non-intuitive.

In this paper we have analyzed strategies that might somewhat ease the channel tensions resulting from the manufacturer's entry into the market as a competitor to its supply chain partner. For example, with Strategy 1, the manufacturer makes no change to the wholesale price and can assure the retailer that she will 
not undercut his price. With Strategy 2, the manufacturer can emphasize that she is not pricing in the new channel to undercut the retailer (as prices are the same in both channels) and that with the introduction of the new channel she is offering a break on the wholesale price. In Strategy 3, the manufacturer only agrees to not undercut the retail price.

Surprisingly, we find that the equal-pricing strategy that optimizes the manufacturer's profit (Strategy 3) also tends to be preferred by the retailer over the other two strategies. Interestingly, the end customer also prefers Strategy 3 in most cases, benefiting from lower prices.

When the web channel is relatively inconvenient and costly (i.e. when $\gamma$ and $C_{W}$ are large), we find that the manufacturer gains only little by moving from Strategy 3 to her optimal (non-equal price) strategy. As $\gamma$ and $C_{W}$ decrease, as we might expect they will over time, the retailer will continue to prefer Strategy 3. Under Strategy 3 the profits of both the retailer and the manufacturer increase as $\gamma$ and $C_{W}$ decrease. The risk to the retailer, however, is that for lower values of $\gamma$ and $C_{W}$, the manufacturer has tremendous incentive to undercut the retailer's prices.

In general, we conclude that the retailer might not necessarily view the entry of the manufacturer as harmful and increased competition but rather as a mechanism for segmenting the market in a way that benefits both the manufacturer and the retailer, particularly if the new channel is not as convenient on average as the existing channel. But like the proverbial frog that jumps out if thrown into boiling water but boils to death if put into water slowly heated, the retailer is endangered if the manufacturer, in her new channel, subsequently abandons the equal-pricing policy when the web channel becomes as convenient as the traditional channel.

Possible extensions to our current work might explore strategies for the retailer to mitigate the effect of the manufacturer's entry. It may be possible to interpret the purchase effort by the customers as a negative quality level. A successful strategy for the retailer might be to increase the quality of the purchase experience in ways that are difficult for the direct channel to match. This might include a greater emphasis on in-store environment (e.g. coffee and cookies at bookstores) or adding services (e.g. repair of electronic equipment or aftermarket configuration of equipment at a computer store). As long as the quality level at the retail store is 
sufficiently higher than the Internet channel, the manufacturer will not have incentive to abandon the equalpricing strategy.

Many manufacturers that have recently introduced a web channel appear to have adopted an equalpricing policy. We conclude that such a policy may be reasonable as long as the web channel is significantly less convenient on average than the traditional channel and/or costs in the new channel are greater than costs in the traditional channel. Such a policy might also minimize potential channel conflict with traditional partners. Our research suggests that retailers might be wary of the long-term ramifications of their manufacturer's introduction of a direct channel. If average web convenience and/or costs decline significantly, the manufacturer will have a strong incentive to abandon the equal-pricing policy - and to thus boil the traditional retailer frog.

\section{Appendix}

An extended appendix including all intermediate steps is available from the authors upon request.

\section{Sufficient Condition on R to Guarantee an Interior Point Solution}

The following condition on $\mathrm{R}$ is sufficient to guarantee that the optimal price in the base case and Strategies 1, 2, and 3 is an interior point solution (i.e., $P>R-\alpha_{i}$ for each channel $i$ ):

$$
\begin{aligned}
& R<\operatorname{Min}\left(\bar{R}_{1}, \bar{R}_{2}, \bar{R}_{3}, \bar{R}_{4}\right), \text { where } \bar{R}_{1}=C_{T}+4 \alpha_{T}, \bar{R}_{2}=C_{T}+\frac{16}{5} \alpha_{W}, \\
& \bar{R}_{3}=\frac{C_{T} \alpha_{T}+2 C_{W} \alpha_{T}-5 \alpha_{T}^{2}+C_{T} \alpha_{W}-2 \alpha_{T} \alpha_{W}}{3 \alpha_{T}+\alpha_{W}}, \text { and } \\
& \bar{R}_{4}=\frac{C_{W} \alpha_{W}+2 C_{T} \alpha_{W}-5 \alpha_{W}^{2}+C_{W} \alpha_{T}-2 \alpha_{W} \alpha_{T}}{3 \alpha_{W}+\alpha_{T}} .
\end{aligned}
$$

\section{Proof of Theorem 1}

i) With the wholesale price as in the base case, the retailer chooses the retail price $P_{1}^{*}$ to maximize his profit $\Pi_{1 R}=\frac{\left(R-P_{1}\right)\left(-C_{T}+2 P_{1}-R\right)\left(P_{1}-R+2 \alpha_{W}\right)}{4 \alpha_{T} \alpha_{W}}$. This profit function is cubic with a negative 
coefficient at $P_{1}^{3}$, such that the larger solution to the (quadratic) first order necessary condition is the sole candidate for an interior optimum, $P_{1}^{*}=\frac{\left(C_{T}+5 R-4 \alpha_{W}+\sqrt{\left(C_{T}-R\right)^{2}+4\left(C_{T}-R\right) \alpha_{W}+16 \alpha_{W}{ }^{2}}\right)}{6}$.

Then $P_{1}^{*}>P_{b} * \Leftrightarrow\left(-C_{T}+R+2\left(-4 \alpha_{W}+\sqrt{\left(C_{T}-R\right)^{2}+4\left(C_{T}-R\right) \alpha_{W}+16 \alpha_{W}{ }^{2}}\right)\right) / 12>0$

$$
\Leftrightarrow 2 \sqrt{\left(C_{T}-R\right)^{2}+4\left(C_{T}-R\right) \alpha_{W}+16 \alpha_{W}^{2}}>C_{T}-R+8 \alpha_{W} .
$$

The term on the right hand side of this inequality is positive and squaring both sides and simplification gives $\left(C_{T}-R\right)^{2}>0$.

ii) Substituting $P_{1}^{*}$ into $\Pi_{1 R}$ and comparing retailer profits across the scenarios after some simplification gives $\Pi_{1 R} *<\Pi_{b R} * \Leftrightarrow 4\left(C_{T}-R\right)^{2}+13\left(C_{T}-R\right) \alpha_{W}+32 \alpha_{W}^{2}>0$.

The term on the left hand side of this inequality is a quadratic function. Evaluation of this function at its minimum $R=\frac{13 C_{T}+32 \alpha_{W}}{13}$ gives $\frac{4096 \alpha_{W}{ }^{2}}{169}>0$.

iii) For interior solutions, the difference function $\Pi_{1 M} *-\Pi_{b M} *$ is strictly decreasing in $C_{W}$ (the retail price is independent of $C_{W}$ such that a decrease in $C_{W}$ increases the manufacturer's margin in scenario 1 , but it does not affect the base case scenario). The unique solution to $\Pi_{1 M} *=\Pi_{b M} *$ is given by the threshold value

$$
\bar{C}_{W}{ }^{(1)}=\frac{\left\{\begin{array}{l}
54\left(C_{T}-R\right)^{2} \alpha_{W}-\left(C_{T}-R-4 \alpha_{W}+X\right)\left(C_{T}{ }^{2}-8 C_{T} R+7 R^{2}-12 C_{T} \alpha_{T}-\right. \\
\left.60 R \alpha_{T}+28 C_{T} \alpha_{W}-4 R \alpha_{W}+48 \alpha_{T} \alpha_{W}-32 \alpha_{W}{ }^{2}+X\left(C_{T}-7 R-12 \alpha_{T}+8 \alpha_{W}\right)\right)
\end{array}\right\}}{6\left(C_{T}-R+12 \alpha_{T}-4 \alpha_{W}+X\right)\left(C_{T}-R-4 \alpha_{W}+X\right)},
$$

where $X=\sqrt{\left(C_{T}-R\right)^{2}+4\left(C_{T}-R\right) \alpha_{W}+16 \alpha_{W}^{2}}$

\section{Proof of Theorem 2}

For a given wholesale price, the retailer's profit function is concave and retailer profits are maximized by setting the retail price

$$
P_{2}^{*}=\frac{C_{T}+2 R+B_{2}-2 \alpha_{W}+\sqrt{\left(C_{T}-R+B_{2}\right)^{2}+2\left(C_{T}-R+B_{2}\right) \alpha_{W}+4 \alpha_{W}{ }^{2}}}{3} \text {. This price equals the base }
$$

case price for the wholesale price $B_{2}^{*}=\frac{\left(R-C_{T}\right)\left(5 C_{T}-5 R+16 \alpha_{W}\right)}{8\left(C_{T}-R+4 \alpha_{W}\right)}$.

i) $B_{2} *<B_{b} * \Leftrightarrow-\frac{\left(C_{T}-R\right)^{2}}{8\left(C_{T}-R+4 \alpha_{W}\right)}<0$, which is true since $R<C_{T}+4 \alpha_{W}$ for all interior solutions. 
ii) Comparing retailer profits at these optimal prices across the scenarios after some simplification gives $\Pi_{2 R}^{*}>\Pi_{b R}^{*} \Leftrightarrow \frac{\left(C_{T}-R\right)^{4}}{256 \alpha_{T} \alpha_{W}\left(C_{T}-R+4 \alpha_{W}\right)}>0$, which again is true since $R<C_{T}+4 \alpha_{W}$ for interior solutions.

iii) For interior solutions, the difference function $\Pi_{2 M} *-\Pi_{b M} *$ is strictly decreasing in $C_{W}$. The unique solution to $\Pi_{2 M} *=\Pi_{b M} *$ is given by the threshold value

$$
\bar{C}_{W}{ }^{(2)}=\frac{-\left\{\left(C_{T}-R\right)\left[\left(3 C_{T}-11 R\right)\left(C_{T}-R\right)-16\left(C_{T}+3 R\right) \alpha_{T}\right]+16 \alpha_{W}\left(C_{T}{ }^{2}+3 R^{2}-12 R \alpha_{T}-4 C_{T} R-4 C_{T} \alpha_{T}\right)\right\}}{8\left(C_{T}-R+8 \alpha_{T}\right)\left(C_{T}-R+4 \alpha_{W}\right)} .
$$

\section{Proof of Corollary 1}

$\frac{\bar{C}_{W}{ }^{(2)}}{\partial \gamma}=-\frac{\left(C_{T}-R\right)^{3} \alpha_{T}}{2\left(C_{T}-R+8 \alpha_{T}\right)\left(C_{T}-R+4 \alpha_{W}\right)^{2}}>0$, which is true since $R<C_{T}+8 \alpha_{T}$ for all interior solutions.

\section{Expressions for the Centralized Scenario}

$P_{C}^{*}:$ see proof of Theorem 3

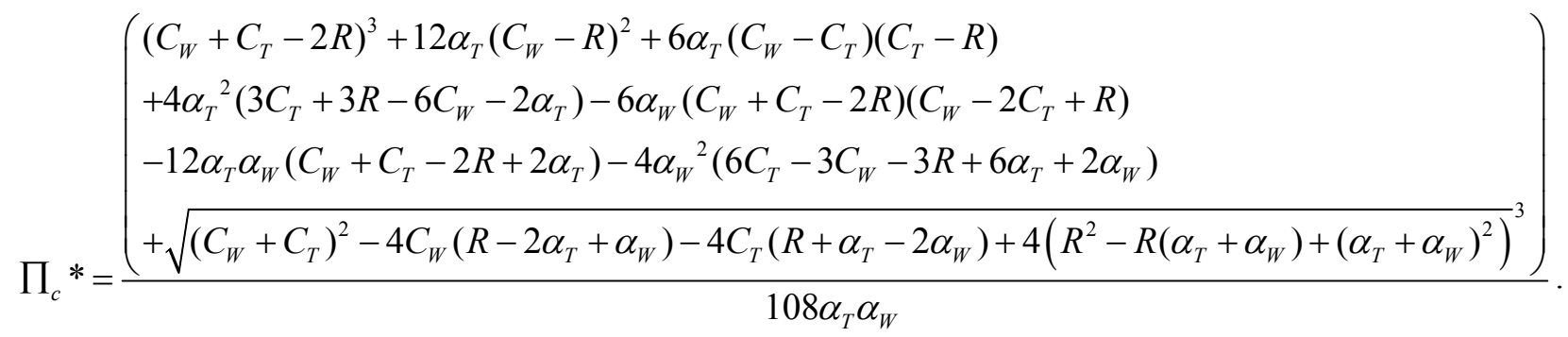

\section{Proof of Theorem 3}

The system profit function

$$
\Pi_{c}=\frac{(P-R)\left[C_{W}\left(P-R-2 \alpha_{T}\right)-2 P\left(P-R+\left(\alpha_{T}+\alpha_{W}\right)\right)+C_{T}\left(P-R+2 \alpha_{W}\right)\right]}{2 \alpha_{T} \alpha_{W}} \text { is a cubic function with a }
$$

negative coefficient on $P^{3}$, such that the larger solution to the (quadratic) first order necessary condition is the sole candidate for an interior optimum,

$$
\begin{aligned}
P_{C} *= & \frac{C_{T}+C_{W}+4 R-2 \alpha_{T}-2 \alpha_{W}}{6} \\
& +\frac{\sqrt{\left(C_{T}+C_{W}+4 R-2 \alpha_{T}-2 \alpha_{W}\right)^{2}+12\left[R \alpha_{W}-C_{T} R+C_{T} \alpha_{W}-\left(C_{W}+R\right)\left(R-\alpha_{T}\right)\right]}}{6} .
\end{aligned}
$$

Then $P_{C}^{*}>P_{b} *$ 


$$
\begin{gathered}
\Leftrightarrow 2 \sqrt{\left(C_{T}+C_{W}+4 R-2 \alpha_{T}-2 \alpha_{W}\right)^{2}+12\left[R \alpha_{W}-R C_{T}+C_{T} \alpha_{W}-\left(C_{W}+R\right)\left(R-\alpha_{T}\right)\right]} \\
>C_{T}-2 C_{W}+R+4 \alpha_{T}+4 \alpha_{W} .
\end{gathered}
$$

The term on the right hand side of the inequality is positive because $R>C_{W}$ and $R<C_{T}+4 \alpha_{W}$. Squaring both sides and simplification gives:

$C_{T}{ }^{2}-4 C_{W} R+16 C_{W} \alpha_{T}+2 C_{T}\left(2 C_{W}-3 R-4 \alpha_{T}+4 \alpha_{W}\right)+5 R^{2}-8 R\left(\alpha_{T}+\alpha_{W}\right)>0$.

The difference between the optimal retail price in the centralized scenario $P_{c}^{*}$ and the base case retail price $P_{b}^{*}$ is increasing in $C_{W}$, as

$$
\begin{aligned}
& \frac{\partial}{\partial C_{W}}\left(C_{T}^{2}-4 C_{W} R+16 C_{W} \alpha_{T}+2 C_{T}\left(2 C_{W}-3 R-4 \alpha_{T}+4 \alpha_{W}\right)+5 R^{2}-8 R\left(\alpha_{T}+\alpha_{W}\right)\right) \\
& =4\left(C_{T}-R+4 \alpha_{T}\right)>0 .
\end{aligned}
$$

The threshold value that solves the equality corresponding to inequality (A1) is

$$
\bar{C}_{W}{ }^{(c)}=\frac{-C_{T}{ }^{2}+2 C_{T}\left(3 R+4\left(\alpha_{T}-\alpha_{W}\right)\right)+R\left(-5 R+8\left(\alpha_{T}+\alpha_{W}\right)\right)}{4\left(C_{T}-R+4 \alpha_{T}\right)}
$$




\section{References}

Ahn, H., I. Duenyas and R. Q. Zhang. 2002. Price competition between retailers and manufacturer-owned stores. Working Paper. University of California, Berkeley.

Bell, D. R., Y. Wang and V. Padmanabhan. 2003. The effect of partial forward integration on retailer behavior: An explanation for co-located stores. Working Paper. University of Pennsylvania.

Boyaci, T. 2004. Competitive Stocking and Coordination in a Multi-Channel Distribution System. Working Paper. McGill University, Montreal, Canada.

Cattani, K. D., W. G. Gilland and J. M. Swaminathan. 2004a. Adding a direct channel? How autonomy of the direct channel affects prices and profits.Working Paper. UNC Chapel Hill.

Cattani, K. D., W. G. Gilland and J. M. Swaminathan. 2004b. Coordinating traditional and internet supply chains. D. Simchi-Levi, D. Wu and M. Shen, eds. Supply chain analysis in the ebusiness era. Kluwer Academic Publishers, Boston, MA,

Chiang, W. K., D. Chhajed and J. D. Hess. 2003. Direct marketing, indirect profits: A strategic analysis of dual-channel supply-chain design. Management Science. 49 (1) 1-20.

Ernst\&Young. 2001. Global online retailing: An Ernst \& Young special report.

Hendershott, T. and J. Zhang. 2004. A model of direct and intermediated sales. Working Paper. University of California, Berkeley.

Hotelling, H. 1929. Stability in competition. The Economic Journal. 39 (153) 41-57.

Jeuland, A. and S. Shugan. 1983. Managing channel profits. Marketing Science. 2 (3) 239-272.

Seifert, R. W., U. W. Thonemann and S. A. Rockhold. 2001. Integrating direct and indirect sales channels under decentralized decision-making. Working Paper. IMD, Lausanne, Switzerland.

Srinivasan, V. 1982. Comments on the role of price in individual utility judgments. JAI Press. Greenwhich, CT.

Swaminathan, J. M. and S. R. Tayur. 2003. Models for supply chains in e-business. Management Science. 49 (10) 1387-1406.

Tsay, A. A. and N. Agrawal. 2004a. Modeling conflict and coordination in multi-channel distribution systems: A review. D. Simchi-Levi, D. Wu and M. Shen, eds. Forthcoming in supply chain analysis in the ebusiness era. Kluwer Academic Publishers, Boston, MA.

Tsay, A. A. and N. Agrawal. 2004b. Channel conflict and coordination in the e-commerce age. Production and Operations Management. 13 93-110.

Vandenbosch, M. B. and C. B. Weinberg. 1995. Product and price competition in a two-dimensional vertical differentiation model. Marketing Science. 14 (2) 224-249. 